\title{
APLICAÇÃO DO ROADMAP DMAIC NO GERENCIAMENTO DE ABASTECIMENTO DE LINHA AUTOMOBILÍSTICA
}

\section{APPLICATION OF ROADMAP DMAIC IN AUTOMOTIVE LINE SUPPLY MANAGEMENT}

\section{Filipe Fernandes Caixeta ${ }^{1}$, Deivid Marques Nunes ${ }^{2 *}, \&$ Aline Gonçalves dos Santos ${ }^{3}$}

${ }^{1}$ Universidade Federal de Goiás, UFG. ${ }^{2}$ Faculdade de Engenharia de Produção da Universidade Federal de Catalão. ${ }^{1}$ caixeta.engprod@gmail.com ${ }^{2 *}$ nunesdm@ufg.br ${ }^{3}$ aline_santos@ufg.br

\section{ARTIGO INFO.}

\section{Recebido em: 12.05.2020}

Aprovado em: 18.11.2020

Disponibilizado em: 27.11.2020

\section{Palavras-chave:}

Sistema Kanban; DMAIC; Indústria Automobilística.

\section{KEYWORDS:}

Kanban System; DMAIC; Automotive Industry.

*Autor Correspondente: Nunes, D. M.

\section{RESUMO}

Para que as ordens de produção sejam finalizadas, é necessário que haja transferência de itens de forma correta entre o armazém e a linha de montagem. Nesse contexto, problemas de ordens de produção pendentes de faturamento devido às divergências de saldo é um fator impactante no aumento do lead time do produto. Desta forma, o objetivo geral deste trabalho foi melhorar a acuracidade da transferência de saldo no abastecimento da linha de produção de uma empresa do setor automobilístico. Para isso, a metodologia utilizada foi baseada na aplicação do roadmap DMAIC, desenvolvendo as etapas: define, measure, analyse, improve e control. Definiu-se que a área da administração de materiais que mais tem impacto nas ordens pendentes é o método de abastecimento por sequenciamento, desta forma, selecionou-se a célula de sequenciamento que mostrou maior variabilidade de processos. No período de medição, ocorreram 258 ordens pendentes, pela célula de maior impacto, representando aproximadamente $\mathrm{R} \$ 17.000,00 \mathrm{em}$ horas homens investidas em análises de divergências. Analisando as causas, para reduzir as situações de ordens pendentes, propôs-se realizar mudanças no fluxo do processo, implementar um quadro de gestão da informação e criar um método de sequenciamento dos cartões de identificação. Após o controle da melhoria, conclui-se que as ocorrências de ordens pendentes reduziram. Porém, ainda é necessário ampliar a aplicação das melhorias em todo método de abastecimento sequenciado, procurando reduzir ainda mais as ocorrências.

\begin{abstract}
In order for the production orders to be finalized, the balance must be transferred correctly between stock and line. In this context, pending production order problems due to balance discrepancies is a significant factor in increasing the lead time of the product. In this way, the general objective of this work was to improve the accuracy of the balance in the production line supply in an automotive company. For that, the methodology used was the DMAIC roadmap, developing the steps: define, measure, analyze, improve and control. It was defined that the area of the administration of materials that has the most impact on the pending orders is the method of supplying by sequencing, in this way, the sequencing cell that showed greater process variability was selected. In the measurement period, there were 258 orders pending, by the cell with the greatest impact, representing approximately $\mathrm{R} \$ 17,000.00$ in men hours invested in analyzes of divergences. By analyzing the causes, to reduce pending order situations, it was proposed to make changes in the process flow, implement an information management framework and create a method of sequencing ID cards. After controlling the improvement, it was concluded that the occurrences of pending orders reduced. However, it is still necessary to increase the application of the improvements in every sequenced supply method, trying to further reduce the occurrences.
\end{abstract}


Citação (APA): Caixeta, F. F., Nunes, D. M., \& Santos, A. G. dos (2020). Aplicação do roadmap dmaic no gerenciamento de abastecimento de linha automobilística. Brazilian Journal of Production Engineering, 6(7), 90-109.

\section{INTRODUÇÃo}

A produção de automóveis desempenhou um importante papel para o desenvolvimento da indústria no século XX, após a primeira guerra mundial, quando a fabricação artesanal dos veículos sofreu evolução para a fabricação em massa, devido às novas metodologias de produtividade do trabalho. Destacam-se como principais contribuintes para essa transformação, Henry Ford, fundador da Ford Motor Company e Alfred Pritchard Sloan Jr, presidente da General Motors (1923-937), que tornaram as empresas por eles dirigidas em gigantes industriais, cooperando com o progresso econômico dos Estados Unidos da América (EUA) (Pimenta, 2002).

A indústria automobilística ainda apresenta grandes contribuições para a indústria, constituindo, segundo Muneer, Kolhe e Doyle (2017), um dos principais setores para os países mais desenvolvidos e contribuindo significativamente para as receitas do governo em todo o mundo. Os autores ressaltam que os automóveis são fabricados com produtos de diferentes indústrias, incluindo aço, ferro, alumínio, plásticos, vidro, carpetes, têxteis, chips de computador, borracha, entre outros, o que gera um nível de produção equivalente a um volume de negócio global. Além disso, a cada emprego direto nesse setor, cinco empregos indiretos são sustentados na comunidade.

Para Pimenta (2002), a indústria automobilística vem passando por várias e importantes transformações, tanto na concepção do valor agregado dos produtos, quanto nos processos pelos quais estes passam para serem concebidos. Essas transformações têm ocorrido desde o surgimento do setor automotivo, cabendo destacar um importante acontecimento que trouxe novas modificações necessárias no setor, que foi surgimento de entrantes no mercado, na década de 1970. Além de provocar mudanças pela emergência das montadoras japonesas no cenário internacional, houve a introdução de inovadores métodos de organização e de gestão da produção criados e desenvolvidos pela Toyota Motor Corporation (Womack, Jones, \& Roos, 1991; Clark, \& Fujimoto, 1991; Fujimoto, 1999).

Nesse cenário, destaca-se a importância da administração da produção que, para desenvolver seu papel de suporte aos objetivos estratégicos da organização, deve ser capaz de orientar e apoiar na tomada de decisões logísticas. Dentre as diversas atribuições, a capacidade de programar a produção para garantir que os recursos produtivos envolvidos estejam sendo utilizados, em cada momento, nas atividades certas e prioritárias é fundamental para o destaque produtivo e, consequentemente, financeiro da organização (Correia, Gianesi, \& Caon, 2007).

Harea, Marian, Moica e Al-akel (2018) destacam que os gestores de produção enfrentam um grande desafio que é de acompanhar a alta competição, as mudanças constantes do ambiente econômico e a escassez dos recursos. Nesse cenário, as empresas devem ter um nível de qualidade desejado e ter eficiência quanto ao tempo, tendo em vista que seus objetivos constituem na excelência industrial, na entrega do produto de qualidade e na quantidade desejada, no prazo e na manutenção de baixos custos de produção.

Correia et al. (2007) acrescenta que outro desafio recorrente em grandes organizações, é que além de garantir que a quantidade correta de matéria-prima esteja fisicamente no lugar e hora certa e qualidade exigida, é necessário que a administração da produção garanta que o saldo 
Citação (APA): Caixeta, F. F., Nunes, D. M., \& Santos, A. G. dos (2020). Aplicação do roadmap dmaic no gerenciamento de abastecimento de linha automobilística. Brazilian Journal of Production Engineering, 6(7), 90-109.

sistêmico (quantidade de itens no sistema) seja o mesmo do físico (quantidade de itens real) no fluxo inteiro. Desta forma, um dos grandes objetivos do gerenciamento de inventário, é garantir que o saldo sistêmico da matéria prima, acompanhe o saldo físico a cada elo do ciclo produtivo (Correia et al. 2007).

Se houver divergência de saldo físico e sistêmico, podem ocorrer algumas variabilidades no sistema produtivo e uma delas é a situação em que as ordens de produção se encontram pendentes de saldo no momento necessário, isto é, quando o produto está acabado, inspecionado e é necessário o faturamento para a venda. No momento da finalização da ordem de produção, o sistema responsável por agregar os dados realiza um processo de verificação de saldo da lista de materiais utilizados na construção do produto final e, se algum dos itens não possuir saldo sistêmico neste momento, a ordem se torna pendente (Hyde, 1981).

Uma das formas de minimizar essas variabilidades é tornar o processo de transferência mais robusto, isto é, à prova de erros dentro de uma margem probabilística. Um meio para isso é a aplicação da metodologia do Lean Seis Sigma, que busca a robustez e padronização de processos produtivos (Peruchi, 2014).

Nesse contexto, como parte da estratégia dos Seis Sigmas, destaca-se o método do ciclo DMAIC (Define, Measure, Analyse, Improve e Control). Essa metodologia, de acordo com Farsi et al. (2020), é um procedimento passo a passo usado para definir possíveis áreas de melhorias, alinhadas a um conjunto de ferramentas e métodos de atuação.

Portanto, diante do contexto exposto, o presente trabalho foi desenvolvido com objetivo geral de, por meio da aplicação de um roadmap DMAIC, aumentar a acuracidade do processo de transferência de saldo no abastecimento de uma linha de produção em uma empresa do setor automobilístico.

\section{REFERENCIAL TEÓRICO}

\subsection{DMAIC}

A filosofia Seis Sigmas visa diminuir a variedade do processo sem afetar a qualidade do resultado (Ikumapayi, Akinlabi, Mwema \& Ogbonna, 2020). No contexto da sua filosofia, temse a metodologia DMAIC, acrônimo para define, measure, analyze, improve e control (Sindha $\&$ Suthar, 2017). De acordo com Krishnan e Prasath (2013), o DMAIC pode ser definido como um roteiro para solução de problemas e melhoria de produto/processo.

Ressalta-se que esse modelo é uma evolução do ciclo PDCA (Plan, Do, Check, Act) e visa manter o processo sob controle por meio da análise de possíveis melhorias no desempenho atualmente desenvolvido. Sendo assim, o objetivo é identificar e entender os problemas-base do processo por meio de dados coletados, determinando ações capazes de eliminar as causas que impedem o melhor resultado (Rotondaro, 2013).

Werkema (2011) enfatiza que o DMAIC é um roadmap detalhado sobre como realizar cada uma das atividades do método, dando ênfase no planejamento para que as ações sejam executadas com propriedade. A aplicação do roadmap permite análises com profundidade adequada, conclusões sólidas e manutenção dos resultados ao longo do tempo (Werkema, 2011). 
Citação (APA): Caixeta, F. F., Nunes, D. M., \& Santos, A. G. dos (2020). Aplicação do roadmap dmaic no gerenciamento de abastecimento de linha automobilística. Brazilian Journal of Production Engineering, 6(7), 90-109.

Das etapas do DMAIC, o primeiro passo é definir o escopo do projeto, em relação aos requisitos e necessidades dos clientes e aos impactos nos processos e estratégias da empresa. Para isso, algumas ferramentas podem ser utilizadas, como por exemplo: Quality Function Deployment (QFD), carta de controle, diagrama espinha de peixe, análise de Pareto e processo de hierarquia analítica (Chakrabortty, Biswas, \& Ahmed, 2013).

No segundo passo, de acordo com Sokovic, Pavletic e Pipan (2010), são medidas as características principais do processo, o escopo dos parâmetros e seus desempenhos. Assim, na etapa de medição, descobre-se o desempenho do processo atual e o foco do problema, uma vez que se coletam os dados. É importante destacar a relevância do sistema de medição/inspeção utilizado, para garantir uma confiabilidade nos dados coletados. Como ferramentas, utiliza-se, por exemplo: o cálculo de capacidade do processo, folha de verificação, amostragem, plano de coleta de dados, índices de capacidade (Rotondaro, 2013; Werkema, 2011).

$\mathrm{Na}$ etapa seguinte, analisar, é feita a identificação de fatores de influência e causas que determinam o comportamento Crítico para a Qualidade (Mast \& Lokkerbol, 2012). Assim, é feita uma análise e determinação das causas do problema, em que todos os fatores são levantados e os prioritários e fundamentais são trabalhados. São utilizados mecanismos, como: Failure Mode and Effect Analysis (FMEA); diagrama de causa e efeito; brainstorming; teste de hipóteses; matriz de priorização (Rotondaro, 2013; Werkema, 2011).

Na etapa de aperfeiçoar, soluções potenciais são desenvolvidas e avaliadas. Assim, as melhores são selecionadas e uma solução piloto é desenvolvida e implementada (Tohidi, \& Khedriliraviasl, 2012). Para auxiliar no desenvolvimento dessa etapa, Rotondaro (2013) Werkema (2011) ressaltam que planos de ação são elaborados e o Delineamento de Experimentos (DOE) pode ser aplicado, além da realização de testes na operação e de mercado.

Por fim, o último passo do DMAIC é manter o controle do processo e da meta estabelecida. Assim, segundo Pyzdek e Keller (2010), é importante desenvolver planos de controle para cada processo-chave e estes devem ser preparados por equipes de pessoas que entendem o processo. Os autores ainda destacam que, inicialmente, deve-se criar um fluxograma do processo, pois ele mostrará como os elementos se relacionam entre si e ajudará na seleção dos pontos de controle. Ele também mostrará o ponto de entrega ao cliente, que geralmente é um importante ponto de controle, sendo que o cliente pode ser interno. Ferramentas e técnicas úteis para auxiliar nessa etapa podem incluir Brainstorming, Diagrama de campo de força, Gráfico do programa de decisão do processo (PDPC), FMEA.

Diante o exposto, nota-se, conforme evidenciado por Tohidi e KhedriLiraviasl (2012), que as fases do DEMAIC conduzem uma equipe de forma lógica, desde a definição de um problema até a implementação de soluções vinculadas às causas subjacentes e o estabelecimento de melhores práticas para garantir que as soluções permaneçam no lugar.

\subsection{SISTEMA KANBAN}

O controle Kanban, segundo Slack, Chambers e Johnston (2009), é um método de operacionalizar o sistema de planejamento e controle puxado, utilizando cartões com informações dos materiais para realizar as operações de movimentação e abastecimento, se 
Citação (APA): Caixeta, F. F., Nunes, D. M., \& Santos, A. G. dos (2020). Aplicação do roadmap dmaic no gerenciamento de abastecimento de linha automobilística. Brazilian Journal of Production Engineering, 6(7), 90-109.

tornando em sua forma mais simples o jeito de um estágio cliente avisar seu estágio fornecedor sobre a necessidade de mais material a ser enviado. O próprio termo Kanban, na tradução para o português significa cartão ou sinal.

Kiran (2019) ressalta que Kanban pode ser um cartão, um contêiner ou um sinal eletrônico. Em uma linha de manufatura JIT, um kanban é associado a cada lote de manufatura e, finalmente, ao lote acabado, pois quando o material é consumido pela operação subsequente ou por uma venda ao cliente, o kanban é removido do lote consumido e enviado de volta à operação anterior, onde se torna uma ordem de serviço para iniciar a produção do próximo lote. Portanto, Kanban, aciona a ação para reabastecer o que foi consumido.

O kanban é visto por Moura (1989) como uma grande alternativa que, por ser um sistema de baixo custo, muitas organizações podem empregá-lo. Através dele pode-se conseguir produtividade evitando-se gastos com a implantação de sistemas mais sofisticados.

Além disso, de acordo com Schönberger (1982), este sistema de controle pode ser introduzido em qualquer momento, independentemente dos níveis de estoque, porém se seu potencial não for aproveitado para detectar problemas e aumentar a eficiência do sistema, não estará se utilizando o Kanban por completo.

Lage Junior e Godinho Filho (2010) ressaltam que, devido à dificuldade em usar o sistema kanban em seu conceito original em situações tão diversas, variações para o sistema foram criadas para se adaptar adequadamente à realidade específica das empresas.

No sistema de manufatura enxuta, Rahman, Sharif e Esa (2013) destacam que Kanban constitui uma ferramenta que pode controlar os níveis de buffer no sistema para regular a produção. Assim, quando um buffer atinge seu nível máximo predefinido, a máquina é instruída a parar de produzir aquele tipo de peça específico.

Slack, et al., (2009) descreve três tipos diferentes de cartões Kanban, a saber:

1. kanban de movimentação ou transporte: serve para avisar um estágio anterior que o material pode ser destinado para um local específico, ou seja, especifica o tipo e a quantidade de produto que o processo subsequente retira do processo antecedente. Tendo como informações do cartão a descrição do produto, local de retirada e destino.

2. kanban de produção: irá informar para um setor que determinado item pode ser produzido para disponibilidade em estoque, ele conterá informações sobre o processo de produção, materiais necessários e destino para a movimentação depois de concluído.

3. kanban fornecedor: tem a função de avisar os fornecedores que certos materiais ou componentes são necessários em determinados pontos da produção, é o responsável pelo suprimento de material necessário para a fabricação de um determinado lote de produção. Ele possui certa similaridade com o Kanban de movimentação, porém para fornecedores externos.

\section{Metodologia}

Nesta seção, primeiramente, será exposta a classificação da pesquisa realizada, seguida pela caracterização da empresa estudada e descrição do processo investigado. Após isso, o método realizado para o desenvolvimento de cada etapa do DMAIC é mostrado. 
Citação (APA): Caixeta, F. F., Nunes, D. M., \& Santos, A. G. dos (2020). Aplicação do roadmap dmaic no gerenciamento de abastecimento de linha automobilística. Brazilian Journal of Production Engineering, 6(7), 90-109.

\subsection{Classificação da Pesquisa}

O método utilizado na condução de um estudo roadmap DMAIC é considerado experimental. Para Carpinetti, Miguel e Gerolamo (2012), o DMAIC seleciona o que pode ser melhorado em um processo em busca de seu aperfeiçoamento e, através de experimentos, chega-se na solução ótima. Quanto à natureza do problema, os dados utilizados são caracterizados como quantitativos. Segundo Diehl (2004), a pesquisa quantitativa envolve análises estatísticas, o que evita interpretações errôneas ou distorcidas dos resultados.

\subsection{CaRACTERIZAÇÃo da EMPRESA}

O estudo de caso foi desenvolvido em uma montadora automobilística, denominada no presente trabalho de ABC Automotores. Dos mais diversos setores que compõem a empresa, o de administração de materiais é responsável por toda a gestão dos estoques e, por isso, foi o foco do estudo. Em média, são 8.000 itens que fazem parte dos estoques e que são utilizados nas linhas de montagem. Desde parafusos e porcas, a carrocerias e vidros, esses itens precisam ser manuseados e alocados de maneira correta, bem como registrados no sistema da empresa.

\subsection{DESCRIÇÃO DO PROCESSO DE ABASTECIMENTO}

$\mathrm{Na} \mathrm{ABC}$ Automotores, o abastecimento é dividido em métodos e são classificados quanto às características geométricas, valor agregado, e quantidade consumida por produto. Desta forma, os métodos utilizados são conhecidos internamente por: chamada cartão, chamada direta simples, chamada direta sequencial e chamada tubulação.

O abastecimento da linha de montagem acontece por quatro processos diferentes: chamada direta; sequenciado; supermercado; chamada cartão. Cada um desses processos apresenta particularidades e é utilizado em pontos específicos da linha de montagem.

No processo de abastecimento por chamada sequencial, os itens produtivos são levados à linha obedecendo à sequência da programação da produção da empresa. Para isso, conta-se com cerca de 300 itens distribuídos nas linhas de montagem e, todos os itens que respondem à chamada sequencial são classificados assim devido ao fato de serem itens de alto valor e por serem usados em apenas um tipo de veículo.

Ressalta-se que uma mesma linha pode ser utilizada para a montagem de modelos diferentes de veículos e, como os itens utilizados pelo método estudado são relativamente grandes, a utilização de dispositivos exclusivos para transporte de cada um dos itens se torna inviável ao se levar em conta o espaço físico disponível para armazenar o estoque em processo nas linhas de montagem. Desta forma, os dispositivos de transporte são adaptados e subdivididos em locações, com espaços para a enumeração da sequência correspondente para levarem itens de um mesmo grupo, com utilização parecida, mas para modelos de produtos diferentes. Além disso, o estoque da empresa precisa estar capacitado a atender todas as variações da produção respondendo de forma correta à programação da produção emitida.

Os dispositivos de transporte possuem identificações visuais de quais itens devem ser levados à linha de produção, contendo o código do item, que são denominados part numbers, sua descrição, e o part number escrito em código de barras, para facilitar a transferência do saldo do estoque para a linha de montagem por coletores. Quando o abastecedor retira os itens do 
Citação (APA): Caixeta, F. F., Nunes, D. M., \& Santos, A. G. dos (2020). Aplicação do roadmap dmaic no gerenciamento de abastecimento de linha automobilística. Brazilian Journal of Production Engineering, 6(7), 90-109.

estoque, ele libera a transferência de saldo entre estoque e linha de montagem, que havia sido realizada pelo repositor.

Os 300 itens são divididos em nove células de sequenciamento. As células foram definidas seguindo alguns critérios como semelhanças de utilização e de armazenagem e itens que são utilizados na mesma linha de montagem.

\subsection{MÉTODO UTILIZADO PARA A APLICAÇão DO ROADMAP DMAIC}

Para se definir o escopo do projeto, primeiro passo da metodologia DMAIC, observou-se o funcionamento do setor de administração de materiais da empresa analisada, devido à importância da gestão de estoques na estrutura organizacional nas indústrias. Por meio dessa observação, destacaram-se as atividades realizadas entre o estoque e o abastecimento da linha de montagem e as implicações que elas traziam para o sistema gerencial. Diante da análise, o problema a ser investigado foi definido.

A partir dessa definição, na etapa Measure, foram coletados os dados referentes às quantidades de ocorrências de cada um dos métodos de abastecimento. Como parte do processo de resolução destas pendências, uma equipe da área de administração de materiais, Smart Office, que é responsável pelo planejamento e controle de abastecimento da linha e de baixas sistêmicas, faz um controle dos itens que impactam o faturamento de ordens de produção, por meio de planilhas diárias. Os dados coletados correspondiam aos meses de maio a julho de 2018 e foram agrupados semanalmente para o levantamento da quantidade de ordens de produção pendentes por itens do método de abastecimento escolhido para estudo.

$\mathrm{Na}$ etapa seguinte, Analyse, para entender quais as causas geradoras das ordens de produção pendentes de saldo, foi feito uma coleta de dados e realizado um brainstorming com colaboradores que estavam em contato direto com o processo. Além disso, o gráfico de Pareto foi elaborado para verificar as causas mais frequentes relacionadas ao problema identificado.

Diante das análises, na etapa de Improve, ações foram sugeridas com base na relação existente entre os erros de procedimento no sequenciamento, as ordens de produção pendentes e as principais causas relacionadas. As propostas de melhoria foram implementadas e os resultados medidos, após três meses da implementação.

Por fim, após a implementação da melhoria e posterior medição do novo nível de desempenho do processo, realizou-se o controle e, para tanto, foi necessário documentar as mudanças para que elas se mantivessem em vigor.

\section{RESUltados E DisCUSSÃo}

Nesta seção, os resultados obtidos a partir da realização de cada etapa do DMAIC são descritos. Também, as discussões são expostas de acordo com o desenvolvimento da metodologia.

\subsection{ETAPA DEFINE}

A partir da observação das atividades realizadas entre o estoque e o abastecimento da linha de montagem, pode-se identificar um problema surgido no abastecimento da linha por chamada sequencial relacionado às divergências de saldos sistêmico e físico que pode ser observado na Fig. 1. Pode-se verificar que o método de abastecimento sequencial ultrapassou a tolerância 
Citação (APA): Caixeta, F. F., Nunes, D. M., \& Santos, A. G. dos (2020). Aplicação do roadmap dmaic no gerenciamento de abastecimento de linha automobilística. Brazilian Journal of Production Engineering, 6(7), 90-109.

máxima aceitável (definida pela organização) e que apesar de ser apenas o segundo em volume de dispositivos transferidos, isto é, demandar menor esforço logístico, supera o método de abastecimento "chamada cartão" em percentual de divergências em 1,17\%.

Figura 1. Relação das Ordens de Produção Pendentes e Total de Dispositivos Transferidos por Método de Abastecimento entre os meses de Maio e Julho.

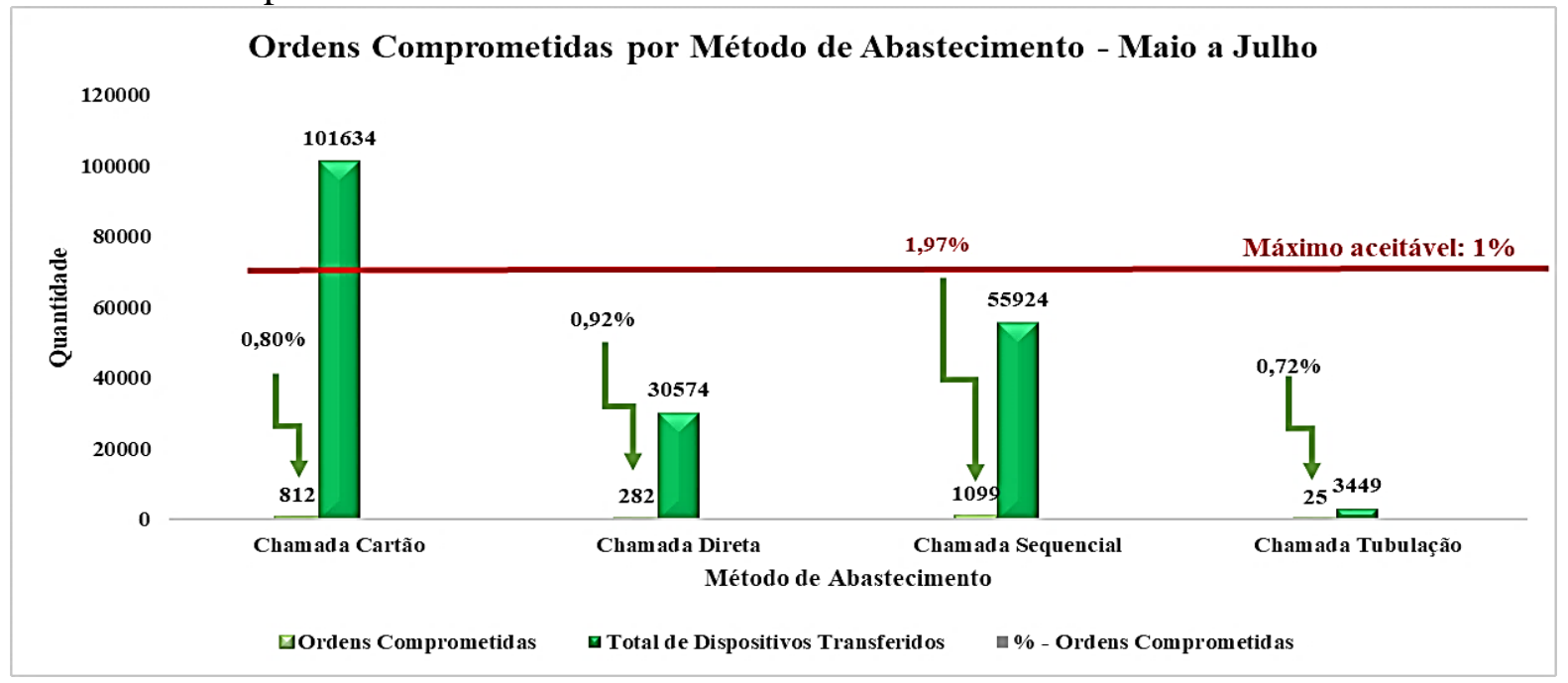

A partir desses resultados, levantou-se dados sobre a ocorrência da quantidade de ordens de produção pendentes por divergência de saldo por célula de sequenciamento conforme mostrado na Fig. 2. Como pode ser observado, a célula 3 foi responsável por 21,66\% das divergências da "chamada sequencial", das ordens de produções pendentes. Assim, ela foi analisada de forma aprofundada e constituiu o projeto piloto para a aplicação do roadmap DMAIC.

Figura 2. Relação das ordens de produção pendentes por células de sequenciamento entre os meses de maio e julho.

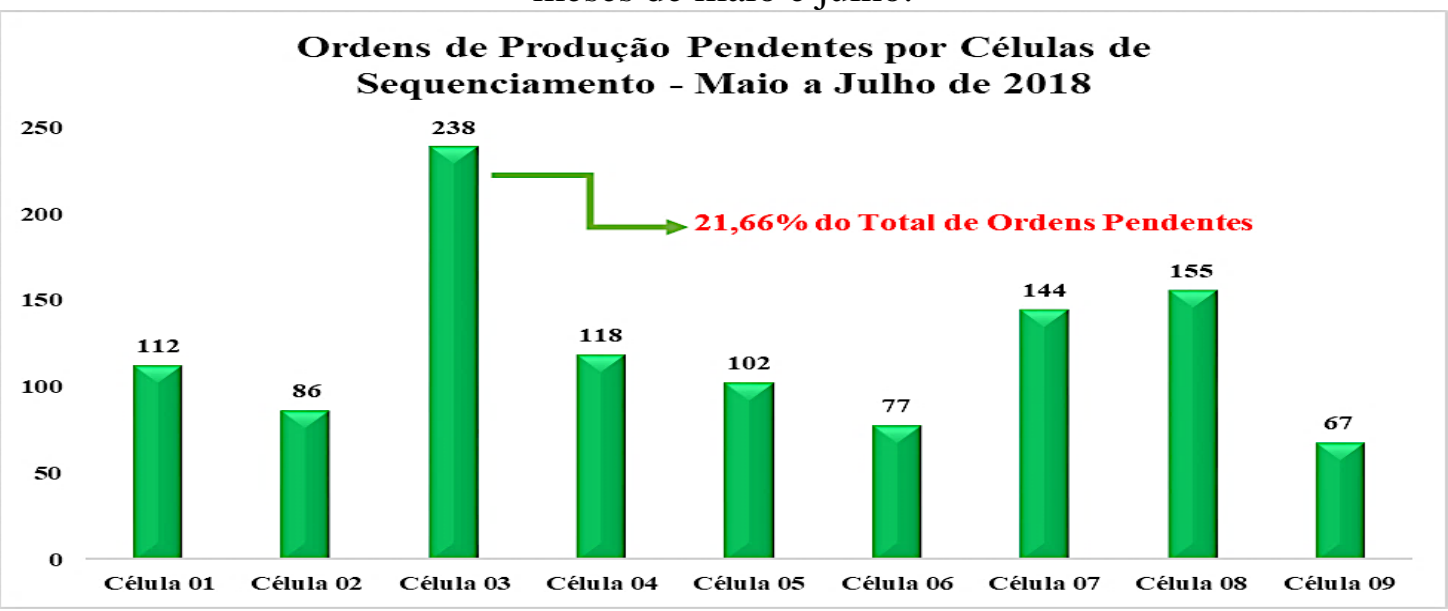

Ressalta-se que a célula 03 é responsável pelo sequenciamento de guarnições de acabamento, tendo 34 itens disponíveis para sequenciamento para quatro pontos de uso diferentes na linha, que possuem quatro dispositivos de transportes, respectivamente.

O fluxo de abastecimento para os quatro pontos de uso diferentes da célula 03 é o mesmo: o departamento de Planejamento e Controle da Produção (PCP) emite parte da programação da produção, os repositores a observam, separam os itens de acordo com a quantidade dos modelos

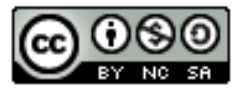


Citação (APA): Caixeta, F. F., Nunes, D. M., \& Santos, A. G. dos (2020). Aplicação do roadmap dmaic no gerenciamento de abastecimento de linha automobilística. Brazilian Journal of Production Engineering, 6(7), 90-109.

dos veículos que serão produzidos, respeitando a quantidade solicitada por unidade pelo BOM (Bill of Material), organizam as peças nas locações dos dispositivos, fazem a compra sistêmica e posterior liberação utilizando o coletor de código de barras para ler o cartão de identificação do dispositivo e, em seguida, o abastecedor responsável pela rota de transporte recolhe o dispositivo montado e, finalmente, abastece o dispositivo de transporte em seu ponto de uso na linha de montagem.

\subsubsection{DEFINIÇÃO DO PROBLEMA}

Apesar de apresentar um funcionamento coeso, percebeu-se a ocorrência frequente de casos em que o ciclo de abastecimento é descontinuado por falta de padronização da etapa de transferência de saldo, isto é, ocasionalmente há divergência da quantidade de saldo transferida física e sistemicamente. Quando isso acontece, é gerada uma situação-problema para o controle de abastecimento de linha, chamada internamente de Smart Office (faça a análises para solucioná-la).

As situações de ordens pendentes de liberação por falta de saldo disponível na linha de produção são como sinalizadores do processo, indicando que o veículo está terminado fisicamente, mas, quando o sistema tenta fazer a agregação da lista de materiais, mensagens de erros são emitidas, pois alguns dos itens (neste caso, itens da célula de sequenciamento 03) não possuem saldo suficiente para consumo da ordem de produção, causando avaria no processo de produção comum.

O processo de resolução de ordens pendentes envolve três áreas da organização, sendo elas: Logística Operacional, Controle Logístico e Fiscal. O processo se inicia no momento em que a ordem de produção é finalizada e o Fiscal tenta realizar a operação de faturamento da ordem.

Neste momento, o software que agrega todas as informações da empresa (ERP - Enterprise Resource Planning), busca a lista de materiais da ordem de produção, verifica a quantidade necessária de saldo de cada item necessário para produzi-la e verifica também se esta quantidade está disponível na WIP (Work In Process) e, caso esteja, a ordem é finalizada, o produto é faturado e pode ser liberado para embarque.

Caso não esteja, o fiscal verifica os itens da lista de materiais que não possuem saldo e informa ao controle logístico. Assim, o controle logístico entra em contato com áreas do armazém em que esses itens pendentes são armazenados e as informa da pendência.

Por último, as áreas responsáveis pela armazenagem (neste caso, Smart Office) fazem inventário do item, contando o saldo físico da linha de produção e estoque, além de verificar o Kardex (lista que demonstra todas as ordens que consumiram o determinado item em um período de tempo) para verificar se não existiu nenhum consumo errado e, depois de analisado tudo, ajustase o saldo e a ordem está liberada para o faturamento e consequentemente embarque.

\subsection{ETAPA MEASURE}

Na Figura 3, é mostrada a relação de ocorrências de ordens pendentes no método de abastecimento sequenciado. Nota-se que a célula 03 representa cerca de $23 \%$ dos problemas totais do sequenciamento e que na semana 01 , sua contribuição chegou a $44 \%$ do total. Por outro lado, na semana 07 , sua contribuição chegou ao mínimo de $13 \%$, o que quer dizer que 
Citação (APA): Caixeta, F. F., Nunes, D. M., \& Santos, A. G. dos (2020). Aplicação do roadmap dmaic no gerenciamento de abastecimento de linha automobilística. Brazilian Journal of Production Engineering, 6(7), 90-109.

apesar da célula 03 ser a maior responsável ao longo do tempo pelas ordens de produção pendentes, em algumas situações, seu percentual de contribuição é menor que de outras células, isso pode ser justificado devido o processo não ser padronizado e controlado.

Figura 3. Relação das ocorrências de ordens pendentes no método de abastecimento sequenciado, de maio a julho de 2018, subdivididos em semanas.

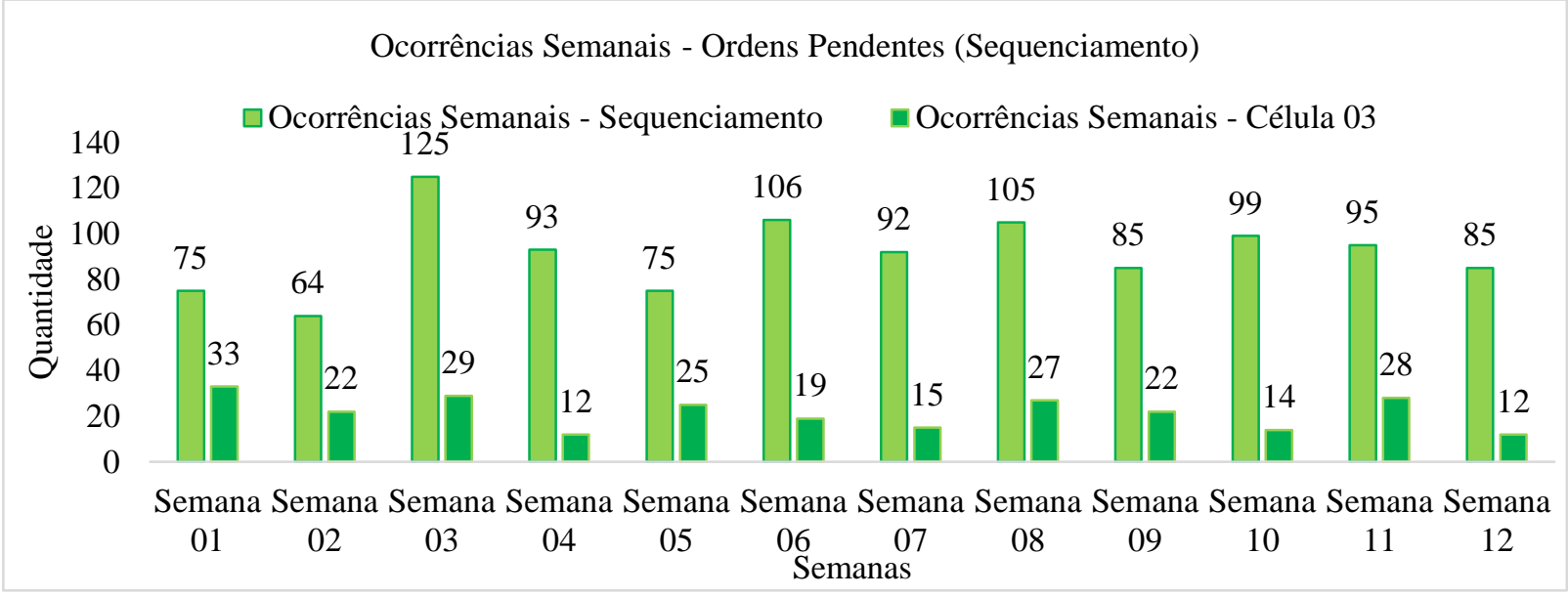

Na Tabela 1, são apresentadas ocorrências de ordens pendentes para o ano de 2018, de maio a julho. Nela, observa-se que o processo de sequenciamento da célula 03 apresentou menor controle que o sequenciamento de forma geral. Isso pode ser percebido ao observar que o desvio padrão amostral da célula de sequenciamento 03 é cerca de $33 \%$ de sua média, enquanto que no processo total, o desvio padrão amostral atingiu $17 \%$ da média.

Tabela 1. Ocorrências de Ordens Pendentes para o ano de 2018, de maio a julho.

\begin{tabular}{ccc}
\hline & $\begin{array}{c}\text { Ordens Pendentes - Total } \\
\text { Sequenciamento }\end{array}$ & $\begin{array}{c}\text { Ordens Pendentes - Célula de } \\
\text { Sequenciamento 03 }\end{array}$ \\
\hline Soma & 1099,00 & 258,00 \\
\hline Média & 91,58 & 21,50 \\
\hline Desvio Padrão Amostral & 16,43 & 7,13 \\
\hline
\end{tabular}

Por meio de um estudo de tempos e métodos foi possível perceber que, em média, era necessário um tempo de 12 minutos para resolver uma divergência de saldo no sequenciamento de matérias-primas, ou seja, 258 minutos por dia, equivalente a $1105 \mathrm{~h}$ e $6 \mathrm{~min}$ horas para um ano de 257 dias úteis ou 128 dias de trabalho de um funcionário. O que representa para a empresa um valor de $\mathrm{R} \$ 17.066,66$.

\subsection{ETAPA ANALYSE}

Com as informações da coleta de dados do brainstorming realizado, desenvolveu-se o diagrama de Ishikawa (Fig. 4), identificando causas das ordens pendentes relacionadas à medida, método, mão de obra, meio ambiente, materiais e máquinas. 
Citação (APA): Caixeta, F. F., Nunes, D. M., \& Santos, A. G. dos (2020). Aplicação do roadmap dmaic no gerenciamento de abastecimento de linha automobilística. Brazilian Journal of Production Engineering, 6(7), 90-109.

Figura 4. Diagrama de Ishikawa para ordens pendentes.

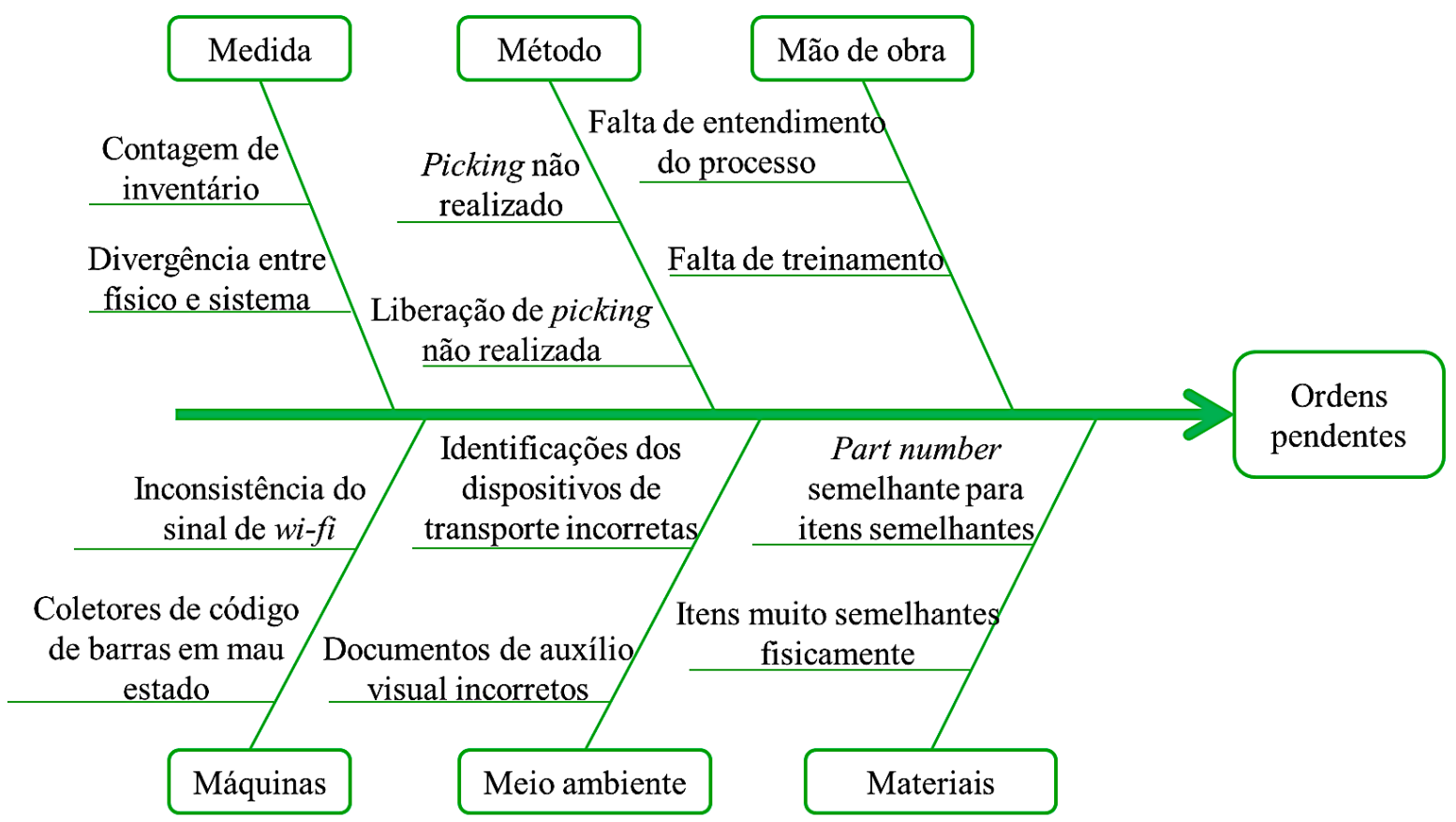

As causas apontadas no aspecto medida correspondiam às quantidades de itens alocadas no estoque e como esses itens eram contados e registrados sistemicamente, sendo elas a contagem de inventário e divergência entre físico e sistema. Já em método, têm-se o picking não realizado e a liberação de picking não realizada, que compõem partes de procedimentos e atividades que permitem o funcionamento e transferência de saldo do estoque para a linha de produção.

Sobre o aspecto mão de obra, as causas determinadas, falta de entendimento do processo e falta de treinamento, se relacionam com ações executadas fora do padrão do procedimento e contribuem para as ordens pendentes. Em materiais, as causas levantadas, itens muito semelhantes fisicamente e part number semelhante para itens semelhantes, tiveram foco nos itens, em suas características e nos procedimentos de desova, conferência, armazenagem e repack.

Em perspectiva do meio ambiente, observou-se que as identificações dos dispositivos de transporte incorretas e os documentos de auxílio visual incorretos são causas relacionadas com a disposição física (auxílios de orientação aos operadores) e organizacional do estoque. Por fim, quanto às causas relacionadas às máquinas, destacaram-se a inconsistência do sinal de wi-fi e coletores de código de barras em mau estado, sendo essas relacionadas com a infraestrutura da empresa e condições de uso de ferramentas de trabalho.

O gráfico de Pareto referente às causas de ordens pendentes no método de abastecimento sequenciado foi realizado, conforme exposto na Fig. 5. Foi possível observar que as causas picking não realizado e picking não liberado estão diretamente relacionadas com o cumprimento do procedimento de transferência de saldo e corresponderam a, aproximadamente, $93 \%$ das ocorrências no período estudado. 
Citação (APA): Caixeta, F. F., Nunes, D. M., \& Santos, A. G. dos (2020). Aplicação do roadmap dmaic no gerenciamento de abastecimento de linha automobilística. Brazilian Journal of Production Engineering, 6(7), 90-109.

Figura 5. Pareto das evidências de causas de ordens pendentes no método de abastecimento sequenciado, de maio a julho de 2018.

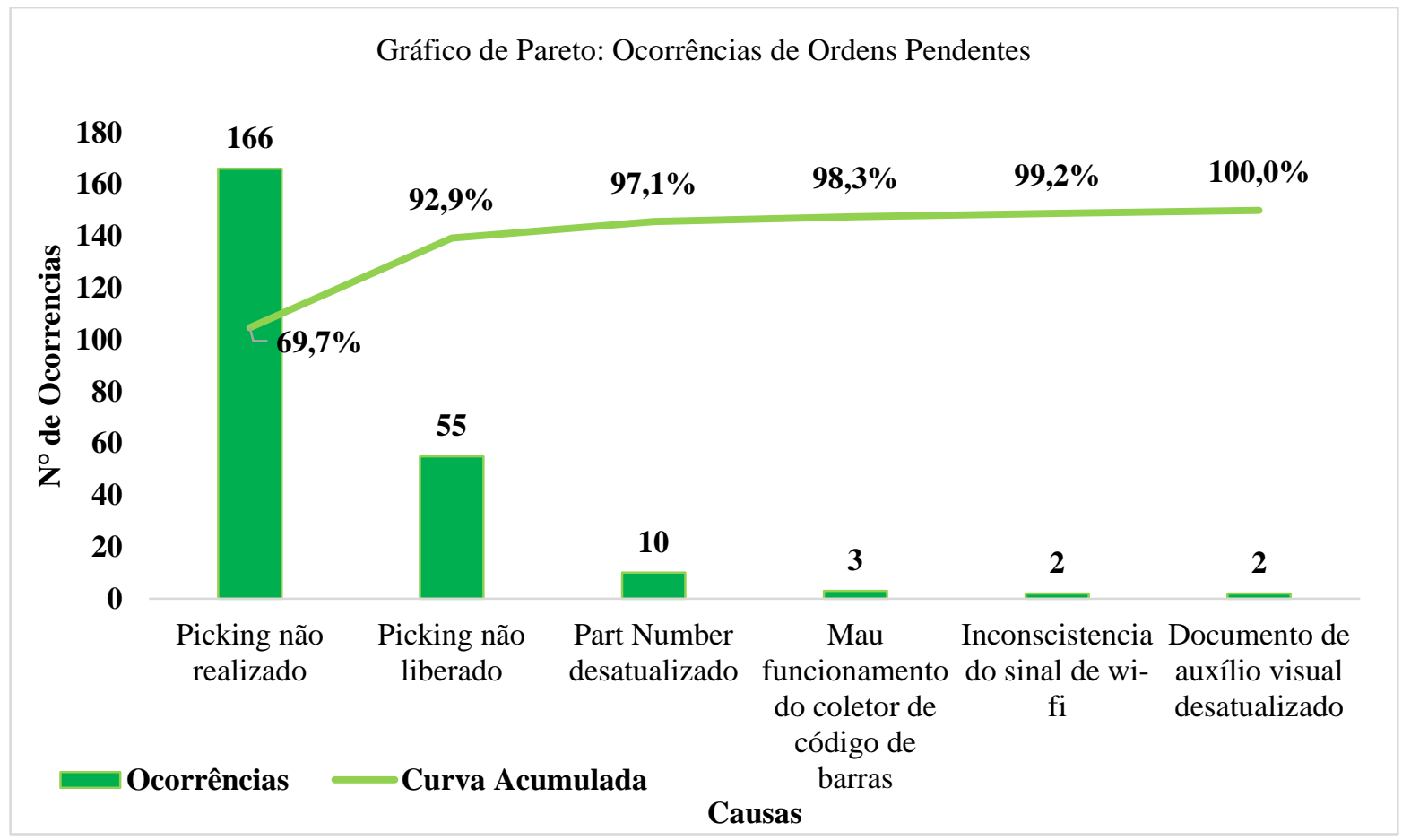

Desta-forma, decidiu-se elaborar melhorias que contemplassem as causas: Picking não realizado e Picking não liberado.

Como o sistema de transferência é basicamente manual, a realização e liberação do picking depende exclusivamente da atenção e do comprometimento dos operadores, isto é, eles são responsáveis pela continuidade do processo. De modo específico, o separador é responsável por: montar dispositivo com itens de produção seguindo programação da produção; realizar processo de picking (compra sistêmica); realizar liberação de picking.

Se o operador errar no processo de picking, o saldo sistêmico não acompanha o saldo físico e, consequentemente, essa divergência causará ordens pendentes em algum momento. Para resolver esse tipo de problema, é necessário o saldo dos itens, mas, se o procedimento fosse seguido à risca, ao tentar liberar o picking, o coletor avisaria que o picking não foi feito e problema seria facilmente resolvido.

Já para a última causa, se o operador não realiza a liberação de saldo, o picking aparece no sistema como "PL" (Pendente de Liberação) e, para resolver este problema, deve-se fazer a leitura do cartão de identificação do dispositivo em que as peças foram transportadas (cartão também utilizado para a realização do picking e liberação).

\subsection{ETAPA IMPROVE}

\subsubsection{MEdidas Propostas}

Em vista da necessidade de se reduzir o número de ordens de produção pendentes, algumas ações podem ser tomadas como propostas que serão apresentadas nesta seção. Ao analisar a relação entre erros de procedimento no sequenciamento e ordens de produção pendentes, bem 
Citação (APA): Caixeta, F. F., Nunes, D. M., \& Santos, A. G. dos (2020). Aplicação do roadmap dmaic no gerenciamento de abastecimento de linha automobilística. Brazilian Journal of Production Engineering, 6(7), 90-109.

como as principais causas relacionadas, percebeu-se que a falta de padronização do processo e a falta de atenção, que causam divergência de picking em relação ao que se transfere fisicamente e sistemicamente são fator de destaque. Assim entende-se a necessidade de padronizar o processo e garantir formas de que as divergências de picking sejam minimizadas.

Para isso, propõem-se a aplicação de medidas Poka Yoke, isto é, medidas à prova de erros, no processo de repack e abastecimento do sequenciamento. Tais medidas serão agregadas às etapas de repack e abastecimento do sequenciamento. Mais do que isso, essa proposta implica em uma mudança na instrução do trabalho dos operadores de repack, e dos abastecedores. Assim, dentro da atribuição de cada um, acrescentam-se novas tarefas no processo que contribuirão para padronizar o processo e minimizar as divergências.

O processo de implementação de medidas Poka Yoke implicou em quatro propostas:

- Criação e enumeração de cartões de identificação dos dispositivos de transporte;

- Redefinição de etapas do procedimento entre Separador e abastecedor;

- Criação de um quadro de memorização de picking diário;

- Promover treinamentos sobre visão sistêmica da organização e entendimento do procedimento;

A primeira proposta trata-se da criação e enumeração de cartões de identificação dos dispositivos de transporte. No procedimento atual, são utilizados identificadores de compra fixados nos dispositivos de transporte para iniciar o processo de picking. O que se sugere é que esse identificador de compra fixado se torne um cartão móvel, enumerado, de 1 ao número máximo de dispositivos de transporte de cada grupo de itens, isto é, se um determinado grupo possui três dispositivos de transporte, os cartões serão enumerados de 1 a 3 com intuito de criar um sistema de sequenciamento de dispositivos.

A sugestão supracitada tem a ver com o fato de que, dois dispositivos de transporte do mesmo grupo de itens não estarão simultaneamente na linha de produção e, assim, se o dispositivo 2 está na linha, o dispositivo 3 está sendo preparado e consequentemente o número 1 estará em fila. De forma prática, serão criadas caixas coletoras destes cartões, denominadas caixa "output" e caixa "input", nas células de sequenciamento e nos dispositivos de transporte. Assim, no momento em que o dispositivo for para a linha de produção, o cartão será retirado da caixa "output" e colocado na caixa do dispositivo e quando retornar, este será retirado da caixa coletora do dispositivo de transporte e será colocado na caixa coletora "input" da célula, em ordem FIFO.

Desta forma, o cartão 1 só poderá ter seu processo de picking iniciado após a finalização do mesmo processo para o cartão 3 e antes do início do processo de picking para o cartão 2. Essas mudanças objetivam evitar a situação de um dos dispositivos ser levado para a linha de produção sem o processo de picking.

Já a segunda proposta se relaciona ao redimensionamento de atividades entre Separador e Abastecedor relacionadas à transferência de saldo. No procedimento, o Separador é responsável por iniciar o picking, finalizá-lo e liberá-lo, utilizando o identificador de compra do dispositivo, porém, se for levado em consideração que a liberação do picking é sequencial à finalização, caso haja um erro na execução do picking, ou até mesmo ocorrer de o Separador não realizá-lo 
Citação (APA): Caixeta, F. F., Nunes, D. M., \& Santos, A. G. dos (2020). Aplicação do roadmap dmaic no gerenciamento de abastecimento de linha automobilística. Brazilian Journal of Production Engineering, 6(7), 90-109.

e, consequentemente, não liberá-lo, o único envolvido em todo o processo será o operador, isto é, não há nenhum tipo de possibilidade de auditoria por parte de seu cliente abastecedor.

Portanto, propõe-se que ao invés de o Separador liberar o picking, o abastecedor seja responsável por isso. Desta forma, na tentativa de liberação de picking através do cartão de compra, caso o abastecedor verifique que nenhum picking foi registrado, a não conformidade será resolvida na fonte e será evitado que futuramente ordens de produção travem por divergência de saldo.

A terceira proposta está relacionada ao arquivamento de informações diárias dos picking da célula. Na prática, serão criados quadros de gestão da informação nas células de sequenciamento, que conterão a coluna para número do cartão de compra, intervalo da programação da produção que foi sequenciado e identificador de picking.

Ao fazer o picking, o Separador anotará no quadro o número do cartão de compra utilizado, e o número da sequência, o intervalo de programação e, no momento em que o abastecedor executar a liberação de picking, anotará o número do picking no quadro.

Por último, a quarta proposta está relacionada ao fato de que em processos manuais, a motivação dos operadores é parte importantíssima para o sucesso do procedimento. Desta forma, promover treinamentos e capacitações que os conscientizem sobre a importância de seu trabalho, sobre os impactos no lead time sempre que ocorram descumprimento do processo fazem com que os colaboradores se sintam parte da organização e essenciais para o seu sucesso.

Por meio da aplicação da melhoria proposta, as principais causas levantadas podem ser combatidas e as situações de ordens de produção pendentes de saldo reduzidas. Caso haja falha no processo de transferência, o analista poderá rastrear o problema de forma eficiente, já que as informações de número do cartão, identificador de picking, intervalo de programação e quantidade de peças de cada um dos itens estarão todas "amarradas" no quadro de gestão da informação.

De forma prática, as três propostas serão capazes de:

- Minimizar os picking não realizados, pois, no momento em que o abastecedor for executar o processo de liberação, não haverá picking há ser liberado caso o mesmo não tenha sido feito e o Separador será informado.

- Minimizar os picking não liberados, pois, no momento em que for levar o dispositivo de transporta para a linha de produção, o abastecedor terá de retirar o cartão da caixa "Output", realizar liberação e inserir na caixa do dispositivo de transporte. Diferentemente do processo atual, em que o abastecedor não participa do processo de liberação do picking, de forma que não possui capacidade de auditoria do processo.

- Promover maior conhecimento dos operadores em relação ao processo como um todo, aumentando o nível de comprometimento e de atendimento aos procedimentos internos da organização.

\subsubsection{IMPLEMENTAÇÃO DAS MELHORIAS PROPOSTAS}

O primeiro passo para a aplicação das medidas propostas foi a construção do quadro de gerenciamento de informações, caixas coletoras e cartões de identificação. O quadro foi confeccionado como planejado, assim como as caixas coletoras e os cartões de identificação, 
Citação (APA): Caixeta, F. F., Nunes, D. M., \& Santos, A. G. dos (2020). Aplicação do roadmap dmaic no gerenciamento de abastecimento de linha automobilística. Brazilian Journal of Production Engineering, 6(7), 90-109.

utilizando-se de materiais de descarte do estoque. O quadro é apresentado na Figura 6. Com o objetivo de facilitar o uso do quadro por todos os colaboradores envolvidos, ele foi fixado em uma posição de fácil acesso dentro da célula de sequenciamento 03.

Figura 6. Quadro de gestão da informação e caixas coletoras output e input.

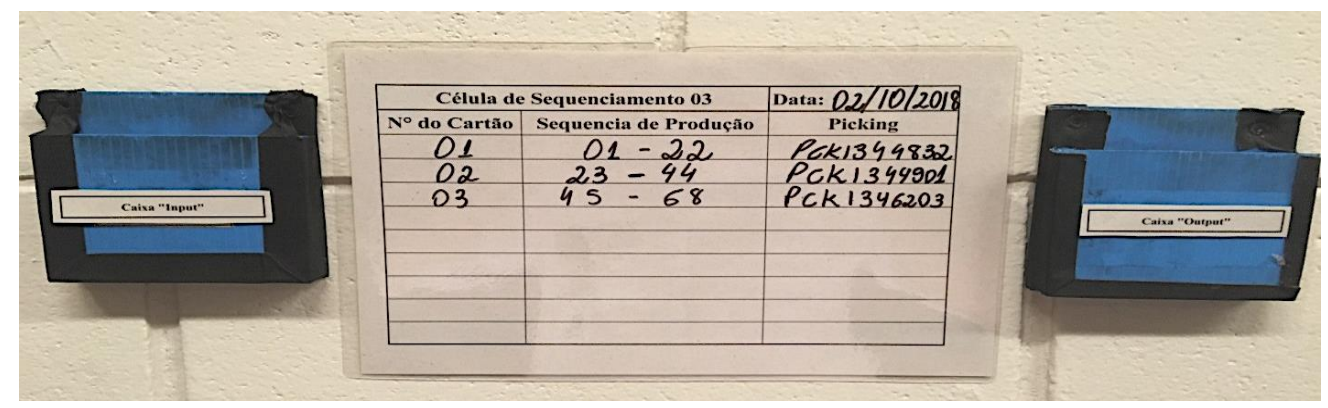

Depois de confeccionados todos os itens necessários, o novo método foi apresentado para todos os colaboradores envolvidos no sequenciamento da célula 03, destacando os objetivos de seu uso e os benefícios agregados à sua aplicação.

Em seguida, realizou-se o treinamento para explicar o uso do quadro de gestão da informação e a movimentação dos cartões durante o processo. No mesmo dia, assim que a produção iniciou, o quadro já começou a ser utilizado, com o suporte de treinamento.

Inicialmente, detectou-se dificuldades iniciais dos operadores em entender o fluxo dos cartões e a nova sequência de operações, o que acabou causando uma maior incidência de ordens de produção pendentes na célula, já que a média diária é de 20,5 e a incidência inicial foi de 22 .

Em seguida, realizou-se um novo treinamento, em que foi destacada a dificuldade em entender a razão da necessidade dos cartões girarem de forma sequencial. Com isso, não foram mais levantadas dificuldades por parte dos operadores durante toda a execução do novo fluxo de abastecimento.

\subsubsection{MediçÃo dos ReSUltados}

Neste tópico, serão apresentados o resultado da implementação das melhorias, após três meses de produção. Na Figura 7, é apresentada a relação de ordens pendentes do método de abastecimento sequenciado detalhado por célula de sequenciamento, no período de agosto a outubro de 2018. Nota-se que a implementação da melhoria elevou a qualidade do processo de transferência de saldo da Célula 03, tendo em vista que a contribuição das pendências de ordem de produção resultantes da célula de sequenciamento 03 reduziu de $21,66 \%$ para $4,77 \%$ em três meses de roadmap, o que corresponde a 198 ordens de produção, resultando em uma redução de 39h e 36 minutos e em valores monetários de $\mathrm{R} \$ 4.880,00$ em análises de inventário em três meses produtivos. 
Citação (APA): Caixeta, F. F., Nunes, D. M., \& Santos, A. G. dos (2020). Aplicação do roadmap dmaic no gerenciamento de abastecimento de linha automobilística. Brazilian Journal of Production Engineering, 6(7), 90-109.

Figura 7. Ordens de produção pendentes por células de sequenciamento entre os meses de agosto e outubro de 2018.

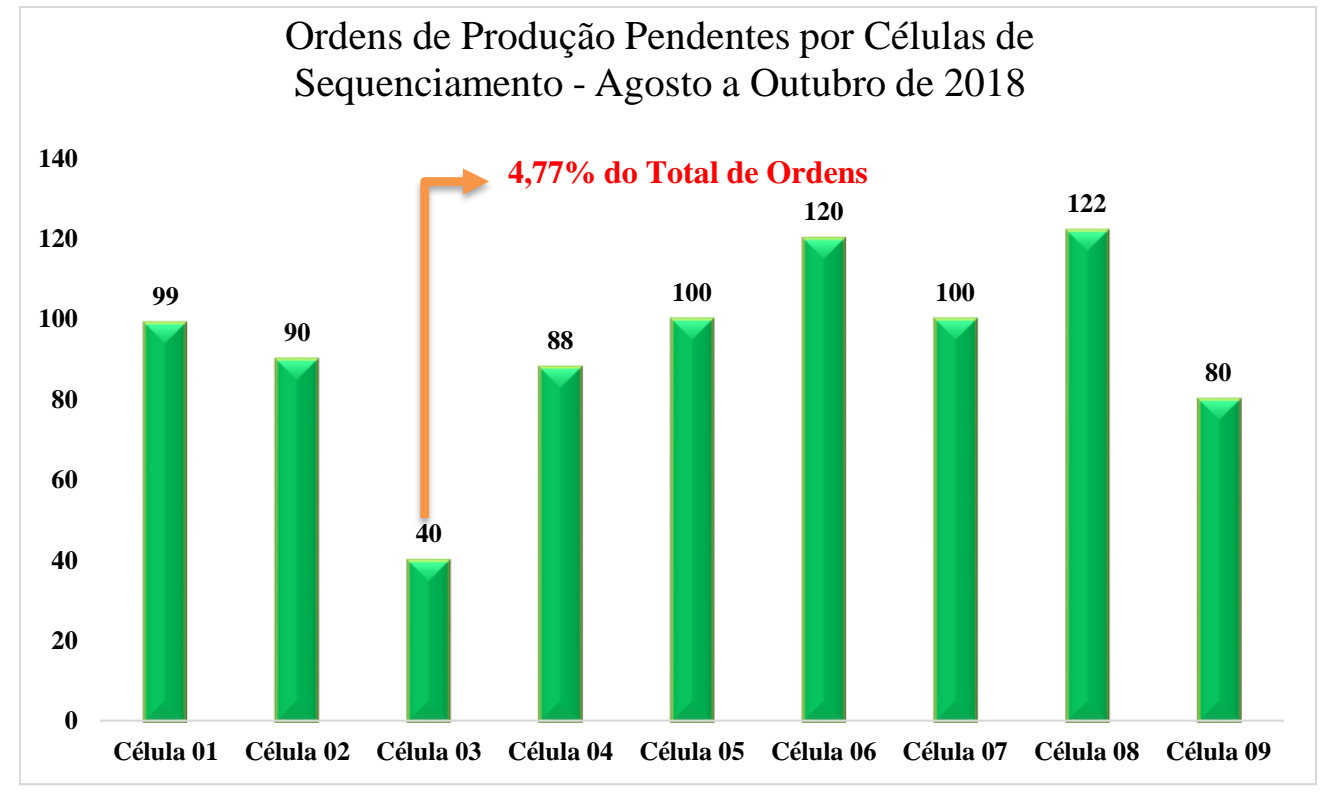

Já a Figura 8 representa a relação de ordens pendentes por método de abastecimento de agosto a outubro de 2018. Observa-se que, na chamada sequencial, de 1,97\% (Fig. 1) passou-se para $1,40 \%$, promovendo uma redução de $0,57 \%$, no percentual de comparação entre o número de dispositivos de transporte de sequenciamento transferidos e o número de ordens de produção pendentes para o período analisado. É interessante ressaltar que essa redução pode ser justificada pela melhora expressiva na célula de sequenciamento 03, visto que esta antes era a maior responsável pela alta variabilidade do processo de sequenciamento.

Figura 8. Ordens Comprometidas por Método de Abastecimento entre Agosto e Outubro de 2018.
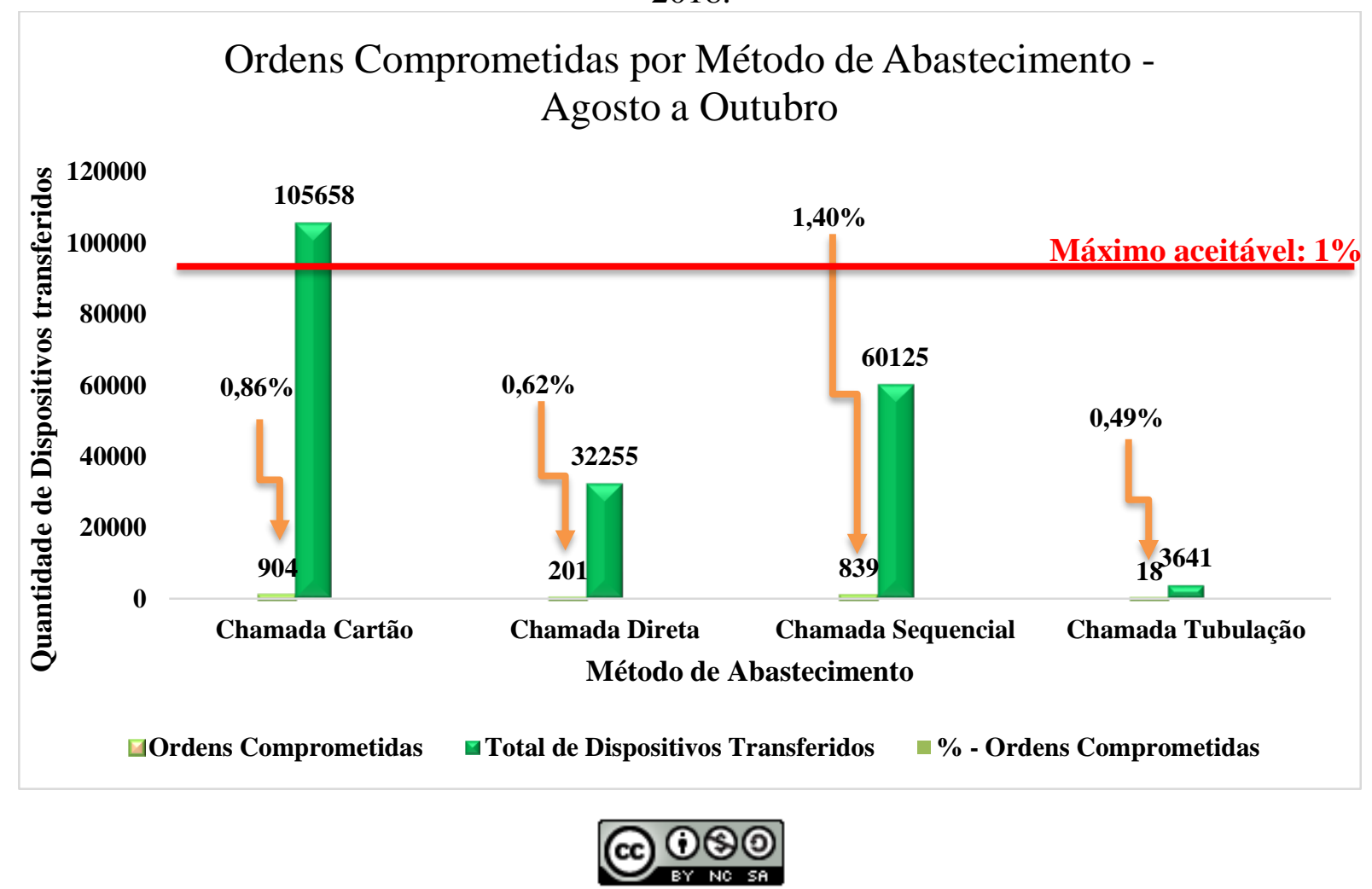
Citação (APA): Caixeta, F. F., Nunes, D. M., \& Santos, A. G. dos (2020). Aplicação do roadmap dmaic no gerenciamento de abastecimento de linha automobilística. Brazilian Journal of Production Engineering, 6(7), 90-109.

Na Figura 9, são detalhadas as ocorrências de ordens pendentes por semana da célula de sequenciamento 03. Percebe-se que, em comparação às demais células, ela melhorou seu desempenho de processo de transferência de saldo e, se comparado ao desempenho do processo anterior, representado pela Fig. 3, a melhoria ainda é mais nítida, já que se percebe que, após a semana 01, semana de implementação, o processo pós-melhoria se tornou além de mais eficaz, mais eficiente e controlado, já que além de as ocorrências diminuírem, a amplitude máxima também diminuiu de 21 para 4.

Figura 9. Ocorrências semanais de ordens pendentes na célula de sequenciamento 03 por método de abastecimento entre agosto e outubro de 2018.

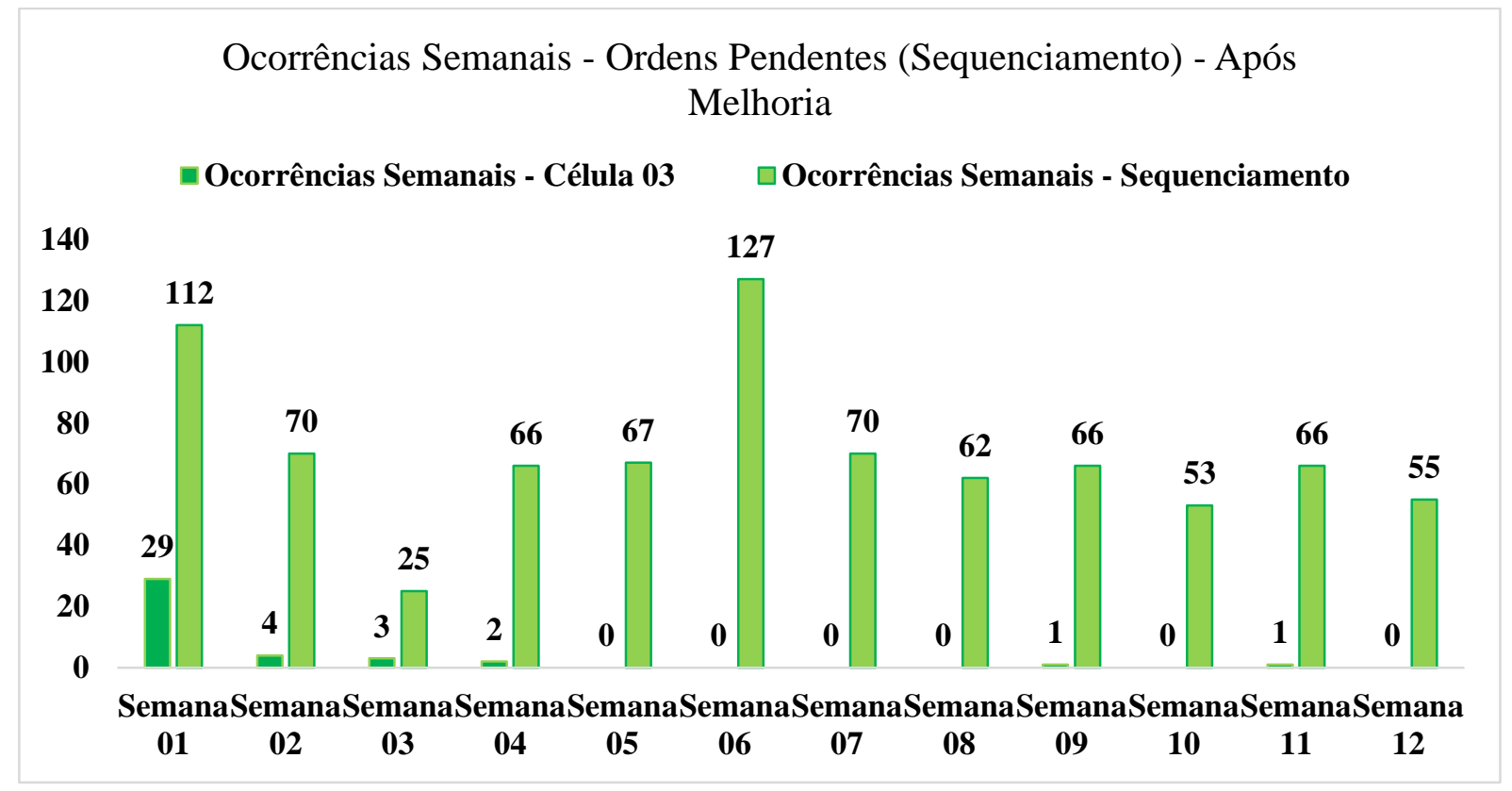

Por último, a Tabela 2, em comparação com a Tabela 1, evidencia a melhora do processo, pois mostra que a média de ordens pendentes no período reduziu de 21,5 para 3,33. Entretanto, o desvio padrão aumentou, porém, se a semana de implementação for excluída (Semana 01 correspondente a 29 ocorrências), a média cairá para 0,916 ordens pendentes por semana e um novo desvio padrão seria de, aproximadamente, 1,5, evidenciando ainda mais a alta padronização de processo causada pela implementação da melhoria. Além disso, essa redução representou aproximadamente $\mathrm{R} \$ 17.000,00$ em horas trabalhadas despendidas em análise de ordens pendentes.

Tabela 2. Ocorrências de Ordens Pendentes para o ano de 2018, de agosto a outubro.

\begin{tabular}{ccc}
\hline & $\begin{array}{c}\text { Ordens Pendentes - } \\
\text { Total Sequenciamento }\end{array}$ & $\begin{array}{c}\text { Ordens Pendentes - Célula de } \\
\text { Sequenciamento 03 }\end{array}$ \\
\hline Soma & 849,00 & 40,00 \\
\hline Média & 70,15 & 3,33 \\
\hline Desvio Padrão Amostral & 25,28 & 7,84 \\
\hline
\end{tabular}


Citação (APA): Caixeta, F. F., Nunes, D. M., \& Santos, A. G. dos (2020). Aplicação do roadmap dmaic no gerenciamento de abastecimento de linha automobilística. Brazilian Journal of Production Engineering, 6(7), 90-109.

\subsection{ETAPA CONTROL}

$\mathrm{Na}$ etapa de controle, o fluxograma do novo procedimento foi adicionado à célula 03 , para que em casos de rotação de operadores, os novos tenham compreensão da metodologia implementada. Além disso, este fluxograma foi adicionado ao sistema de gestão da informação da empresa, para que, caso seja necessário fazer revisões de fluxo, ele estivesse disponível de forma fácil e rápida.

Uma rotina de monitoramento foi estabelecida para que o projeto fosse acompanhado, para assim garantir que o alcance da meta fosse mantido ao longo do tempo. Desta forma, criou-se a rotina de gerar listas com os itens que haviam provocado ordens de produção pendentes para que os próprios operadores de repack analisassem as causas da variabilidade e, posteriormente, criassem planos de ação para prevenção de novos problemas semelhantes.

Sendo assim, tanto a documentação, quanto o monitoramento contínuo fazem parte da implementação da filosofia de melhoria contínua na área de administração de materiais.

\section{CONSIDERAÇÕES FINAIS}

O presente trabalho foi desenvolvido com o objetivo central de melhorar a acuracidade no processo de transferência de itens no abastecimento da linha de produção de uma empresa do setor automobilístico, por meio da aplicação de um roadmap DMAIC.

Pode-se verificar que o abastecimento sequencial foi o método que ultrapassou a máxima aceitável de divergências de $1 \%$, sendo a célula 3, dentre as 9 presentes na organização, responsável por $21,66 \%$. Além disso, constatou-se que $93 \%$ das não conformidades são ocasionadas pelo picking não realizado e o não liberado, sendo necessária a padronização do processo de abastecimento de itens para sua minimização.

Ações com baixa complexidade de implementação, como Poka Yoke, proporcionaram uma redução de $21,66 \%$ para $4,77 \%$ nas pendências das ordens de produção, após um período de 3 meses. Sendo assim, o desenvolvimento das fases da metodologia proporcionou uma redução na quantidade de ordens pendentes pelo método de abastecimento chamada sequencial em, aproximadamente, $95 \%$, no período de agosto a outubro, em comparação ao período de maio a julho.

A implementação do roadmap DMAIC também possibilitou redução de aproximadamente $96 \%$ da média da ocorrência de erros e de, aproximadamente, $70 \%$ no seu desvio padrão. Esses valores demonstram que o processo analisado, além de ter menor incidência de erros, evidenciado pela redução da média, também é mais controlado, já que o desvio padrão reduziu, ressaltando a menor variabilidade do processo.

Além disso, o desenvolvimento do roadmap proporcionou redução de cerca de $\mathrm{R} \$ 17.000,00$ em horas trabalhadas em análise de ordens pendentes, o equivalente a 128h, ou 14 homens/ dia, isto é, como se o analista pudesse deixar de trabalhar 14 dias no período estudado.

Recomenda-se para uma pesquisa futura, expandir a aplicação do roadmap DMAIC na célula de sequenciamento 03 para todas as células do método de abastecimento e, posteriormente para toda a administração de materiais. 
Citação (APA): Caixeta, F. F., Nunes, D. M., \& Santos, A. G. dos (2020). Aplicação do roadmap dmaic no gerenciamento de abastecimento de linha automobilística. Brazilian Journal of Production Engineering, 6(7), 90-109.

\section{REFERÊNCIAS}

Carpinetti, L. C. R., Miguel, P. A. C., \& Gerolamo, M. C. (2012). Gestão da Qualidade: conceitos e técnicas. 2. ed. São Paulo: Atlas.

Correia, H. L, Gianesi, N. G, \& Caon, M. (2007). Planejamento, programação e controle da produção MRPII \& ERP, 5. Ed. São Paulo: Atlas.

Chakrabortty, R. K., Biswas, T. K., \& Ahmed, I. (2013). Reducing Process Variability by using DMAIC Model: A Case Study in Bangladesh. International Journal for Quality Research, p.127-140.

Diehl, A. A. (2004). Pesquisa em ciências sociais aplicadas: métodos e técnicas. São Paulo: Prentice Hall.

Farsi, M., Bailly, A., Bodin, D., Penalla, V., Pinault, P-L., Nghia, E. T. T., Sibson, J., \& Erkoyuncu, J. A. (2020). An Optimisation Framework for Improving Supply Chain Performance: Case study of a bespoke service provider. Procedia Manufacturing, v49, p. 185192.

Fujimoto, T. (1999) The Evolution of a Manufacturing System at Toyota. New York, Oxford University Press.

Clark, K. B., \& Fujimoto, T. (1991). Product Development Performance: Strategy, Organization, and Management in the World Auto Industry. Boston, Haverd Business School Press.

Harea, C. V., Marian, L., Moica, S., \& Al-akel, K. (2018). Case study concerning 5 S method impact in an automotive company. 11th International Conference Interdisciplinarity in Engineering, INTER-ENG, Tirgu-Mures, Romania.

Hyde, W.F. (1981). Improving productivity by classification, coding and data base standardization: the key to maximizing CAD/CAM and Group Technology. New York: M. Dekker.

Ikumapayi, O. M., Akinlabi, E.T., Mwema, F. M., \& Ogbonna, O.S. (2020). Six sigma versus lean manufacturing - An overview. Materials Today: Proceedings. 26, p. 3275-3281.

Kiran, D. R. (2019). Production Planning and Control: A Comprehensive Approach, Elsevier e Book Aid International. p. 369-379.

Krishnan, B. R., \& Prasath, K. K. (2013). Six sigma concept and DMAIC implementation. International Journal of Business. 3, p. 111-114.

Lage Junior, M., \& Godinho Filho, M. (2010). Variations of the kanban system: Literature review and classification. Int. J. Production Economics, 125, p. 13-21.

Mast, J., \& Lokkerbol, J. (2012). An analysis of the Six Sigma DMAIC method from the perspective of problem solving. International Journal of Production Economics, 139, p. 604614.

Moura, R. A. (1989). Kanban; a simplicidade do controle de produção. São Paulo: IMAM.

Muneer, T., Kolhe, M., \& Doyle, A. (2017). Electric Vehicles: Prospects and Challenges, Elsevier, 2017.

Peruchi, R. S. (2014). MDMAIC: um roadmap Seis Sigma multivariado. Tese de Doutorado. Universidade Federal de Itajubá, Itajubá.

\section{(c) (1)}


Citação (APA): Caixeta, F. F., Nunes, D. M., \& Santos, A. G. dos (2020). Aplicação do roadmap dmaic no gerenciamento de abastecimento de linha automobilística. Brazilian Journal of Production Engineering, 6(7), 90-109.

Pimenta, L. J. (2002). A crise nas redes concessionárias de automóvel no Brasil. 157f. Dissertação de Mestrado, Universidade Salvador, Salvador, BA, Brasil, 2002.

Pyzdek, T., \& Keller, P. A. (2010). Six Sigma Handbook: A Complete Guide for Green Belts, Black Belts, and Managers at All Levels. McGraw-Hill Companies, 3ed.

Rahman, N. A. A., Sharif, S. M., \& Esa, M. M. (2013). Lean Manufacturing Case Study with Kanban System Implementation. Procedia Economics and Finance, 7, p. $174-180$.

Rotondaro, R. G. (2013). Seis Sigma: estratégia gerencial para a melhoria de processos, produtos e serviços. 1. ed. São Paulo: Atlas.

Schönberger, R. J. (1982). Japanese manufacturing techniques - nine hideen lessons in simplicity. New York, The Free Press/MacMillan.

Sindha, N., Suthar, K. (2017). Review on Implementation of Six Sigma DMAIC Methodology in Manufacturing Industries. International Journal of Science Technology \& Engineering, 3, p. 168-171, 2017.

Slack, N., Chambers, S., \& Johnston, R. (2009). Administração da produção. 3. ed. São Paulo: Atlas.

Sokovic, M., Pavletic, D., \& Pipan, K. K. (2010). Quality Improvement Methodologies - PDCA Cycle, Radar Matrix, DMAIC and DFSS. Journal of Achivements in Materials and Manufacturing Engineering, 43(1), 476-483.

Tohidi, H., \& Khedriliraviasl, K. (2012). Six Sigma Methodology and its Relationship with Lean Manufacturing System. Advances in Environmental Biology, p. 895-906.

Werkema, C. (2011). Lean Seis Sigma: Introdução às ferramentas do lean manufacturing. 2. ed. Rio de Janeiro: Elsevier.

Womack, J. P., Jones, D. T., \& Roos, D. (1991). The Machine that Change the World. Macmillan, New York, 1991. 